\title{
The Development of a SMS-based Teaching and Learning System
}

\author{
Simon So \\ Hong Kong Institute of Education, Hong Kong
}

\begin{abstract}
The short message service (SMS) technology is one of the most stable mobile technologies around. Most of our tertiary students carry mobile phones with SMS facilities and can be used for teaching and learning. There are many projects of using SMS technologies in education as outlined in the literature review, but many publications do not provide the possible underlying technologies to implement such the teaching and learning systems. In this paper, the development of a SMS-based teaching and learning system is presented. The underlying technology of using GSM modems to build the SMS-based teaching and learning system is revealed. The system is capable of supporting administrative, teaching and learning activities via the SMS technology. Examples of various activities such as brainstorming, voting, and assessment activities supported by the system are illustrated.
\end{abstract}

Keywords: Short Message Services (SMS), e-Learning / m-Learning, GPRS/GSM

\section{Introduction}

In a key-note speech of mLearn 2007, Charlie Schick of Nokia pointed out that the majority of people who own mobile phones only has the basic features (Schick, 2007). We cannot assume learners all carry multimediarich mobile phones, PDAs, UMPCs, netbooks, or notebooks. What we can assume is that most learners such as tertiary students in developing and developed countries only carry basic mobile phones for voice and SMS communication. Therefore, when we consider ubiquitous access (other than Web-based access) to teaching and learning for our students, we must employ basic and trusted technologies such as SMS to connect with our students. This is the guiding principle of this research.
In this paper, the development of a SMS-based teaching and learning system is presented. The literature review of various SMS projects for teaching and learning is given in Section 2. Section 3 reveals the technological considerations of employing the SMS technology to build the system. Teaching and learning considerations are outlined in Section 4. For completeness, the limitations of the system are described in Section 5. Conclusive remarks are provided in Section 6.

\section{Literature Review}

There has been an increasing interest in academic institutions using mobile devices to support teaching and learning. Different mobile 
devices can be used in mobile learning. The most ubiquitous and stable mobile technologies namely Short Message Service (SMS) texting (Traxler, 2005) on cellular phones has great potential in education. For the last 10 years, many SMS projects for teaching and learning were reported in the literature. In this section, some of the projects are highlighted. These projects are being categorized into (a) communication and administrative support, and (b) teaching and learning support as described below.

\subsection{Communication and Administrative Support}

2.1.1. Administrative communication in higher education. Laura Naismith (2007) from the University of Birmingham reported that an e-mail to text message service called StudyLink is employed to support administrative communication in higher education. Text messaging can be "effectively integrated into both the student and staff experience" (p. 155). Administrative staff members were able to integrate the service into their current means of communicating with students while students were able to effectively receive and act on text messages. Message types include notices of changes and cancellations (e.g., class cancellations), reminders to submit and collect assignments, notices of relevant lectures/ activities, individual administration (e.g., warning messages to absentees), instructional messages (e.g., instructions for submitting assignments), and greeting/courteous messages.

Pramsane and Sanjaya (2006) described the development of education services based on short message services. The education information such as the enrolment information, grade release, university announcement, and internship opportunity can be retrieved and/ or sent by the students via SMS through a login system. This research points out that administrative support to students via short message services is ideal.

2.1.2. Library Applications. Library services can be improved through SMS-based administrative support. Libraries can reach out and serve students ubiquitously by sending and receiving SMS-based library information. There are a number of areas in library services for which SMS-based messages can be helpful. Basic information alerts such as notices of book reservations, and renewals and overdue reminders are well tailored with this communication medium. One example is the SMS alert services offered by the Hong Kong Institute of Education (HKIED, 2009). Further library services can also be provided via SMSbased systems. For example, extended text messaging reference can text SMS messages to and receive answers from librarians as reported in Hill, Hill, and Sherman's (2007) research at Southeastern Louisiana University as a way to further enhance the quality of services provided by libraries in higher education.

\subsection{Teaching and Learning Support}

\subsubsection{Classroom interaction and discussion.}

Scornavacca, Huff, and Marshall (2007, 2009) presented a SMS-based classroom interaction system. They called this the TXT-2-LRN system. The system allows students to send questions or comments to the instructor's laptop via SMS. The instructor can read the messages on the screen and decide to respond immediately or wait for later action. The instructor can also provide a quiz to the students and collect results. Students can look at the projector's screen in real-time graphics showing the results.

Markett et. al. (2006) reported using short message services to encourage interactivity in the classroom. The PLS TXT UR Thoughts project involves students sending SMS in real- 
time via their personal mobile phones in class and the lecturer can view the messages during class and online after class from the perspective of interactive message loop - initiating, acknowledging, responding to, and completing between students and lecturer. Tools were built to facilitate the interactivity.

Bollen, Eimler, and Hoppe (2004) implemented a communication and discussion tool based on sending SMS-based messages through the interface of PDAs. Discussions, collaborative work, and cooperative modelling processes are supported by a SMS database. Selected messages can be sorted by sender, receiver, time, and scenario. After specifying the desired messages, a cluster of cards for the relevant messages are visually displayed.

2.2.2. Language Learning. The possibility of learning languages at any time and at any place is highly desirable for busy learners (Cui \& Wang, 2008). SMS technologies were proved by many researchers to be especially effective for language learning like vocabulary learning. The reasons are that discrete SMS messages can be provided in a short and succinct manner, and readily available for learners such as in commuter trains or buses. The learning process is not as interrupting or disturbing as other media like audio or video. An overview of mobile assisted language learning by KukulskaHulme and Shield (2008) also points out another advantage that rather learners are able to obtain the information anytime and anywhere themselves, the mobile devices are ideal for the "push" approach of learning by sending information to the learners at set times and on set days. The scope for discussion here does not restrict to English. Other languages such as Italian (Levy \& Kennedy, 2005) and Greek (Pincas, 2004) were reported in the literature. As there are quite a number of research papers reported in this area, only some projects will be highlighted as follows.
$\mathrm{Lu}$ (2008) explored the application of SMS in second language learning in Taiwan. Similarly, SMS vocabulary lessons were sent to EFL learners and reported the students read their messages literally anytime, everywhere - in commuting, between classes, or even before going to bed. Students preferred to learn through mobile phones than PCs, because mobile phones were more convenient than PCs in this situation.

Thornton and Houser $(2001,2005)$ reported that they use SMS and e-mail to conduct English lessons in Japan. They introduced five words each week to students and sent short mini lessons three times a day via SMS messages. Individual lessons include learning a single word, some facet of a word, examples or reviews, of previously learned words.

Levy and Kennedy (2005) described a project of learning Italian via mobile SMS within an Australian university context. The project was pitched at a course entitled "Italian Literature and Society." Students were sent new words, definitions, and example context sentences to their mobile phones so that they could learn in between the lessons and tutorials of the course. Favourable evaluation and outcomes were reported. Similar reports by the same authors on the topic can be found (Kennedy \& Levy, 2008).

Cavus and Ibrahim (2009) reported an experiment in using SMS to support learning of technical words. Spaced repetitions of the same messages were sent on different days through a SMS-based system called mobile learning tool (MOLT) developed by the authors.

2.2.3. Online Questioning. Ng'ambi and Brown (2009) reported on the use of an anonymous consultation tool. The dynamic frequently asked questions (DFAQ) allowed students to anonymously post questions and 
receive responses from both the teaching staff and the students. The interface of the Web and SMS allowed users to engage with those whose were off campus through mobile phones. Users who posted questions from their cell phones received responses via SMS.

Geoff Stead at CTAD provided a number of case studies ranging from preparing workbased promotional materials, raising literacy to numeracy awareness via sector-based phone and SMS quizzes (Stead, 2005). For example, learners are presented with a study card of a particular content such as "Test your math skills" or "Being a cleaner." After studying the materials, the learners can then answer the questions by texting the answers to the learning center like "Text polish followed by the five numbers of your answers to $07800 * * * * * *$.

2.2.4. Distance Education. In many rural areas, distance education is the only option for some learners. The issues of servicing distance students are very complicated. The importance of the communication infrastructure in teaching and learning is paramount for the success of any distance learning program. A reliable and readily available technology like SMS gives learners opportunities to interact and engage with other learners and instructors. The case for using SMS interventions to support distance education students was reported by Viljoen, Preez, and Cook (2005) from the University of Pretoria, South Africa. In Bangladesh, one of the poorest countries on Earth (Islam \& Doyle, 2008), synchronous and asynchronous interactive communication can be offered via SMS. Islam and Doyle (2008) described how a cellular phone can be financed in Bangladesh and how the SMS technology combined with the nationwide educational television network for distance education.

2.2.5. Other Innovative Applications. Some innovative applications of SMS technologies were reported in the literature. MartínezTorres et. al. (2007) described a SMS-based laboratory environment. In a microcontroller course, students learn the concept about CPU and peripherals using the Motorola $68 \mathrm{HC} 11$ microcontroller. Traditional peripherals were replaced with a more interactive Philip Savvy GSM phone that was electronically connected to the microcontroller. Students needed to send a required SMS message to the professor which could substantially improve their motivation and interest in the laboratory.

Game-based learning is another area for the innovative use of SMS technologies. Goh and Hooper (2007) devised an SMS crossword puzzle system. They explored the feasibility of using SMS facility of mobile phones to promote learning through the use of an SMS crossword puzzle activity in a classroom environment. A puzzle was displayed on the projector screen by the instructor and students needed to send the word through an SMS message. The learning content of various levels could be generated for different classes from the backend database. Motivation and the level of potential adoption of the system were their research questions in this project.

\section{Technological Considerations}

SMS (Short Message Service) is originally available on digital GSM (Global System for Mobile Communications) networks allowing text messages of up to 160 characters to be sent or received. The concatenation mechanism of SMS permits messages longer than 140 bytes. If the phone is powered off or out of range, messages can be conveniently stored in the mobile network operators and are delivered at the next opportunity. SMS is the most reliable and popular message communication on mobile phones today. According to ITU (International Telecommunication Union), in China alone, SMS usage totaled to 250 billions in 2005 . The 
significance of this technology leads to many applications developed for different areas including teaching and learning.

Typically, the exchange of SMS messages requires a SMSC (Short Message Service Center) to store and forward the messages and interact with the mobile network. Applications receive the messages directly from SMSC and send messages out to the SMSC. For a large operation of sending and receiving SMS messages, SMS messages can be sent to the mobile network operator using SMPP (Short Message Peer-to-Peer Protocol). SMPP is an open industry standard messaging protocol designed to simplify integration of data applications with wireless mobile networks as shown in Figure 1.

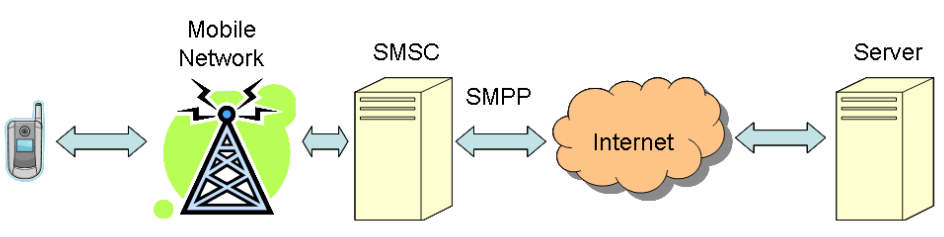

Figure 1. SMS Service API with SMPP

For medium to small operations, there are a number of options available. Some companies, for example, provide SMS services through HTTP, XML, or SMTP. Clients do not have to know the SMS technologies behind this system too much. For example, Telstra Mobile Online SMS Business Service in Australia allows clients to send and receive SMS messages conveniently from their desktop computers using a Web interface or from a proprietary desktop SMS software (Telstra, n.d.). But the most direct method is to use a group of GPRS/GSM modems to send and receive SMS messages. Figure 2 illustrates the infrastructure of our SMS-based teaching and learning system using GPRS/GSM modems.

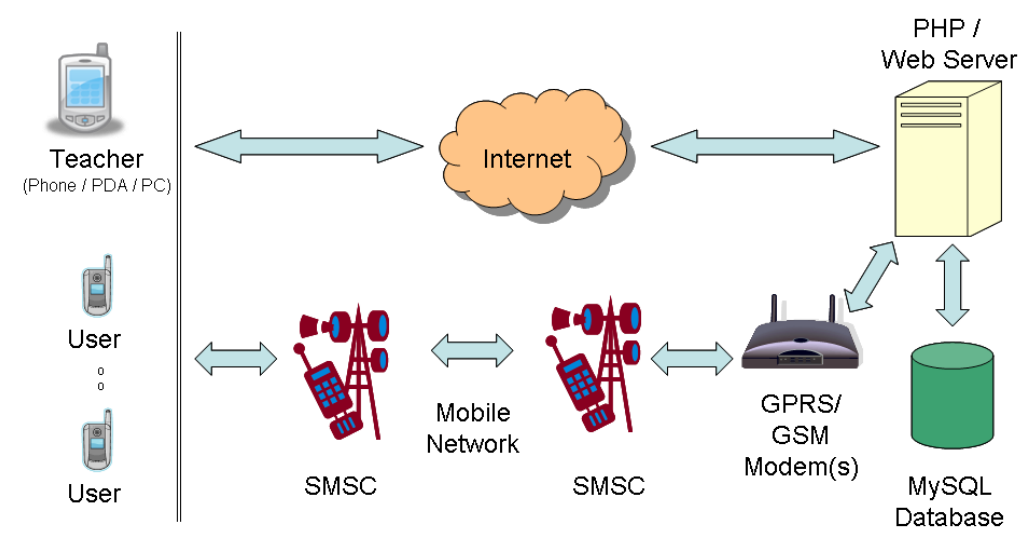

Figure 2. The Infrastructure of the System Using GSM Modems

If GSM modems are used, there are a number of different modems or devices to choose from. Many of them are compatible to the popular Wavecom's GSM modems. These modems are programmed using AT commands to send and receive SMS messages (Wen,
Xiong, Ally, \& Lin, 2006). A comprehensive tutorial on GSM / GPRS Wireless Modems and AT commands can be found in Developershome (2008). For our development, a Fargo GPRS/ GSM modem (a Wavecom compatible modem) is used. Figure 3 shows a minimal setup of our 
system. Apache, PHP, and MySQL were chosen as the Web server, server-side programming and database support respectively.

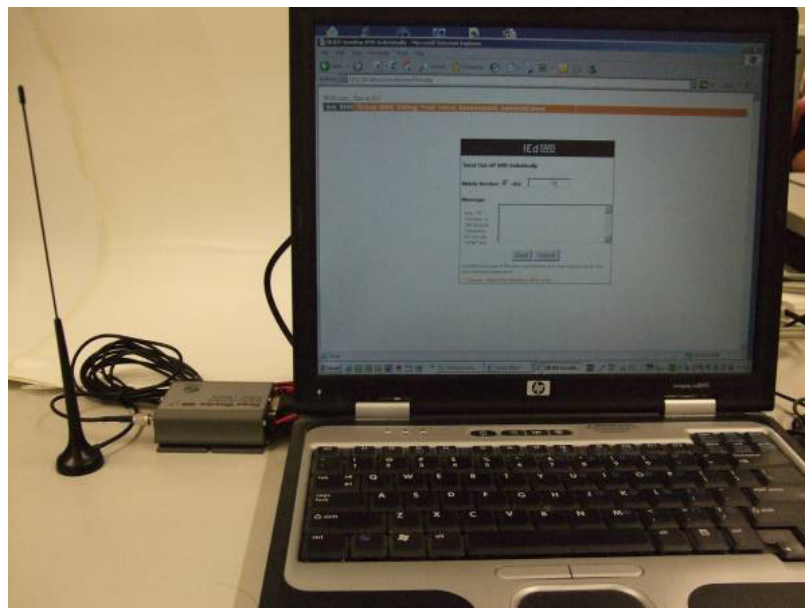

Figure 3. A SMS-based Teaching and Learning System Using a GPRS/GSM Modem
To illustrate how a GPRS/GSM modem works, the basic interaction is shown in Figure 4. A non-Latin message of two Chinese characters encoded with UCS2 is sent to a mobile phone via a sequence of AT commands. The binary PDU mode (e.g., $\mathrm{CMGF}=0$ ) is set to support Unicode. Using a binary mode, message setting, and destination number the message is encoded in a hexadecimal string. The telephone number is encoded so that the message will be delivered to a mobile number in Hong Kong (e.g., 852) from anywhere in the world. In fact, our SMS teaching and learning system is designed to be used globally and transparently. Also, the SMS messages can be relayed to any mobile phone in the world.

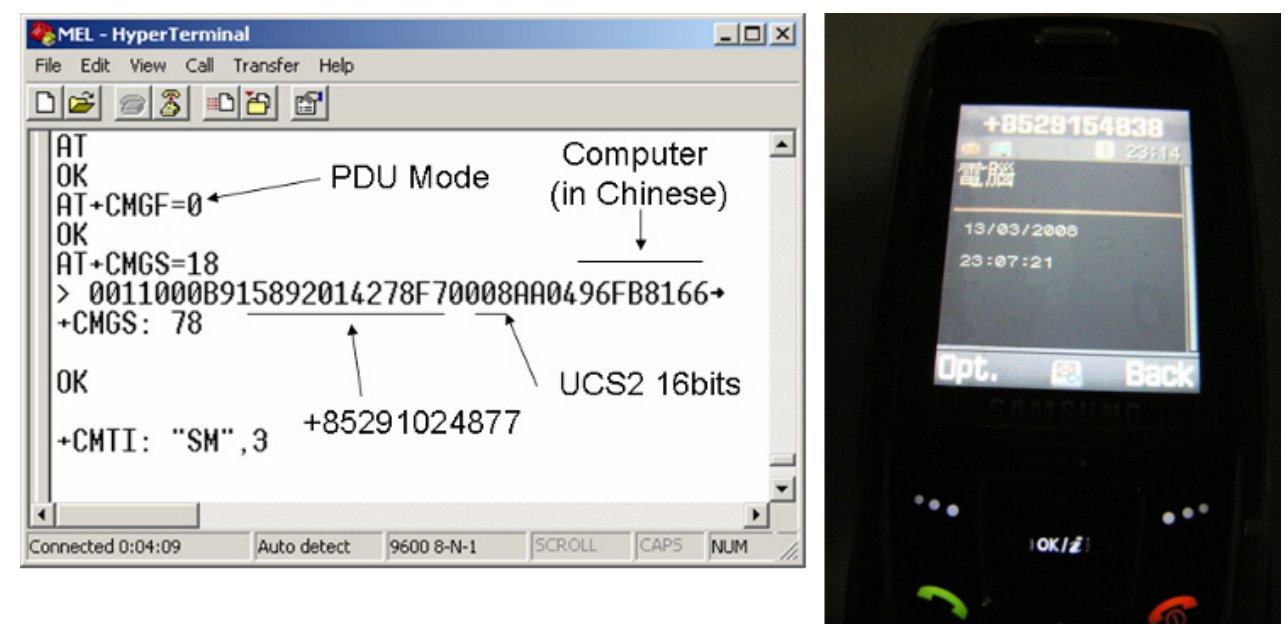

Figure 4. Demonstration of AT Commands

\section{Teaching and Learning Considerations}

Teaching and learning activities in school/ university settings can be facilitated via SMS technologies in a number of ways. Conceptually, we can follow Robert Taylor's arguments on computer use in the early 80s (Taylor, 1980) and equate his arguments to the application of SMS technologies in teaching and learning. Taylor is one of the pioneers in the field of
Information Technology in Education. $\mathrm{He}$ argues that computers can be used as:

1. TOOL: The computer is used to support students to complete tasks associated with learning activities.

2. TUTOR: The computer is used to systematically instruct the student. The intention is for the student to be introduced to skills and knowledge 
through interaction with the software.

3. TUTEE: The computer is instructed by the student. The computer responds to these instructions to simulate learning.

Tool, Tutor, and Tutee can loosely equate and generalize to support, teaching, and learning respectively. These three broad domains should not be viewed in isolation. In fact, depicted in Figure 5, these three domains are overlapped and interacted closely. In a way, our developmental SMS-based teaching and learning system is far from fulfilling all aspects of the three broad domains. However, we identified a few areas or functionalities that may be useful and outlined below.

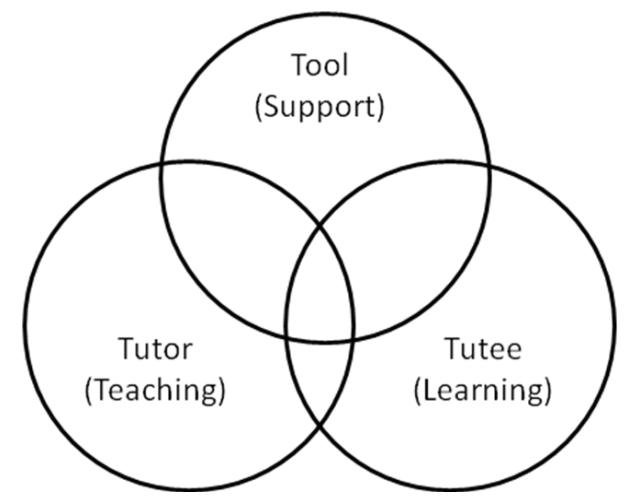

Figure 5. A SMS System Used as a Tool, Tutor, and Tutee

\subsection{Tool: Communication and Administrative Support}

For any e-learning system to be useful and effective, a variety of synchronous and asynchronous communication facilities such as e-mail, chat, and forum should be readily available. The communication facilities should allow student-student, student-teacher, and teacher-teacher communication easily. A SMS system can be very effective to provide communication and administrative support. For examples, students can receive their grades for their units through SMS messages (Deakin,
2009). Alert messages from libraries can be delivered to students (HKIED, 2009). These approaches are increasingly popular in many universities (Naismith, 2007; Pramsane \& Sanjaya, 2006).

Our SMS-based teaching and learning system is capable of providing such support of sending individual or group SMS messages. Teachers can login to the system to send individual SMS messages like in Figure 6. They can retrieve any student's mobile number from a database and send a quick SMS message to the student. The SMS system is also capable of sending a message to a group (e.g., a class of students) retrieved from the database as illustrated in Figure 7. In fact, this capability was proved very effective for the author to deliver an urgent message of cancelling a lesson due to sickness to his students. Furthermore, a teacher can also send group messages such as marks and grades to each student of a class. The messages are conveniently stored in Microsoft Excel XML files to help the teacher to compose the messages easily.

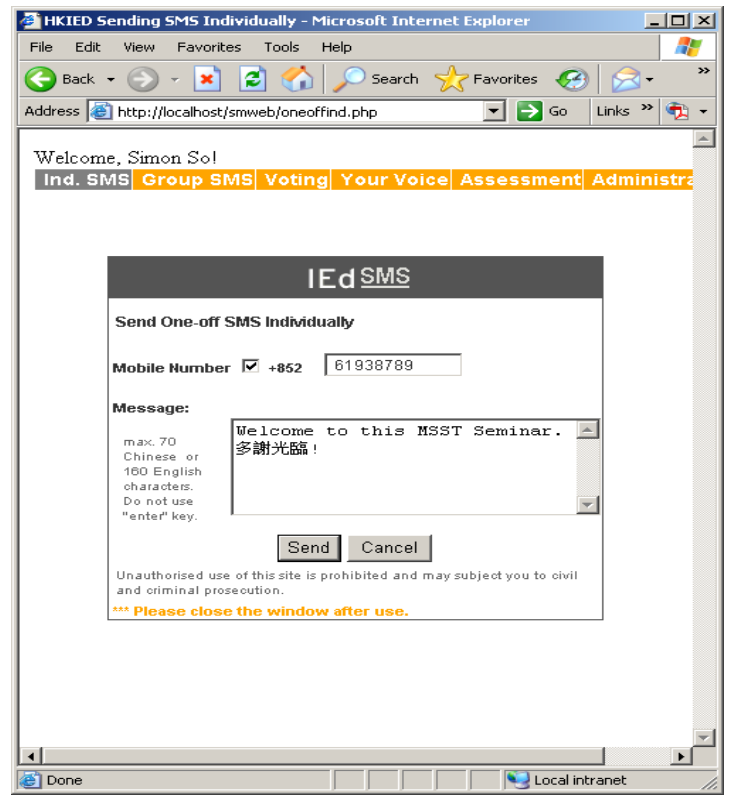

Figure 6. Individual SMS Messages 

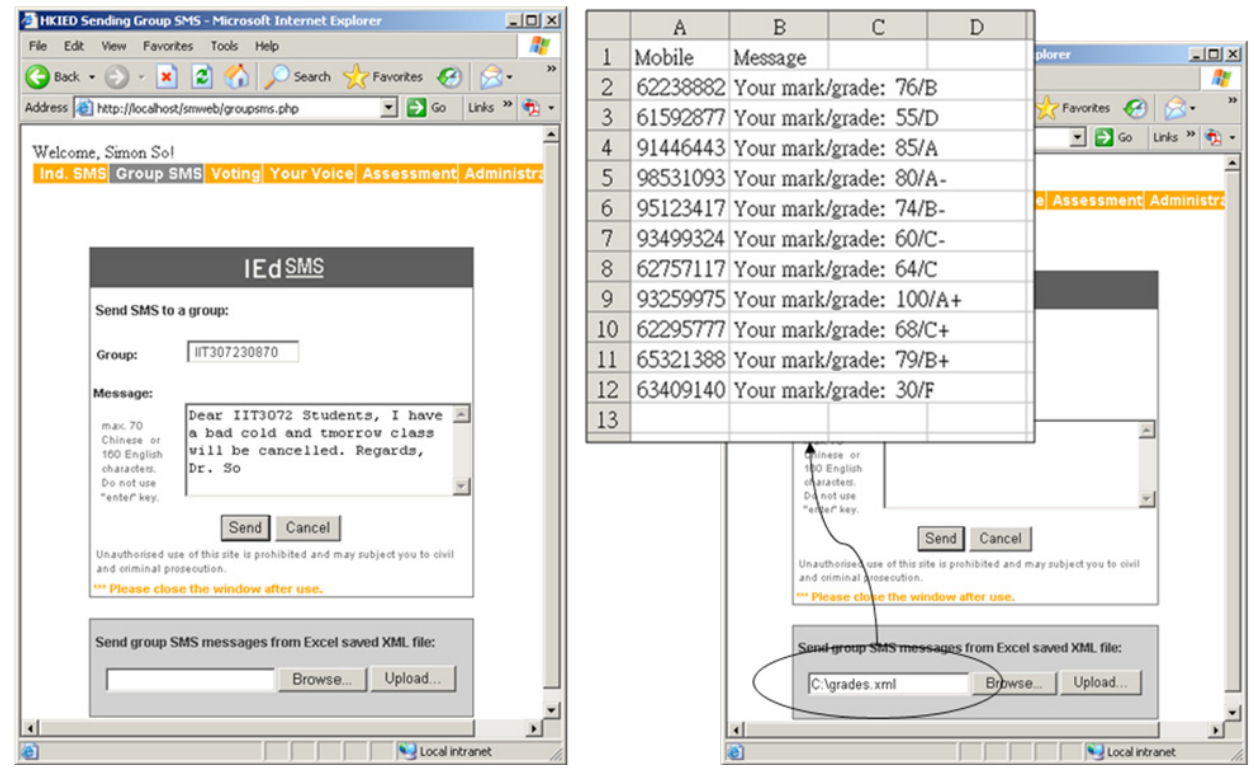

Figure 7. Group SMS Messages Such as Grades and Marks

\subsection{Tutor \& Tutee: Facilitate Teaching and Learning Activities}

For simple didactic instruction, a SMS system can provide fragments of information to the students via SMS messages. For example, like learning Italian described by Levy and Kennedy (2005), we can "push" Chinese idioms or proverbs regularly via SMS messages to students. For more student-centered learning, brainstorming activities can be organized by the teacher. Students can send their ideas using their mobile phones to the system as illustrated in Figure 8. Teachers can show their ideas with their names or anonymously to promote active participation. To engage students in a lecture, student (personal) response systems can be employed (DUKE, 2009). Our system allows students to vote interactively concerning a teacher's questions as shown in Figure 9.
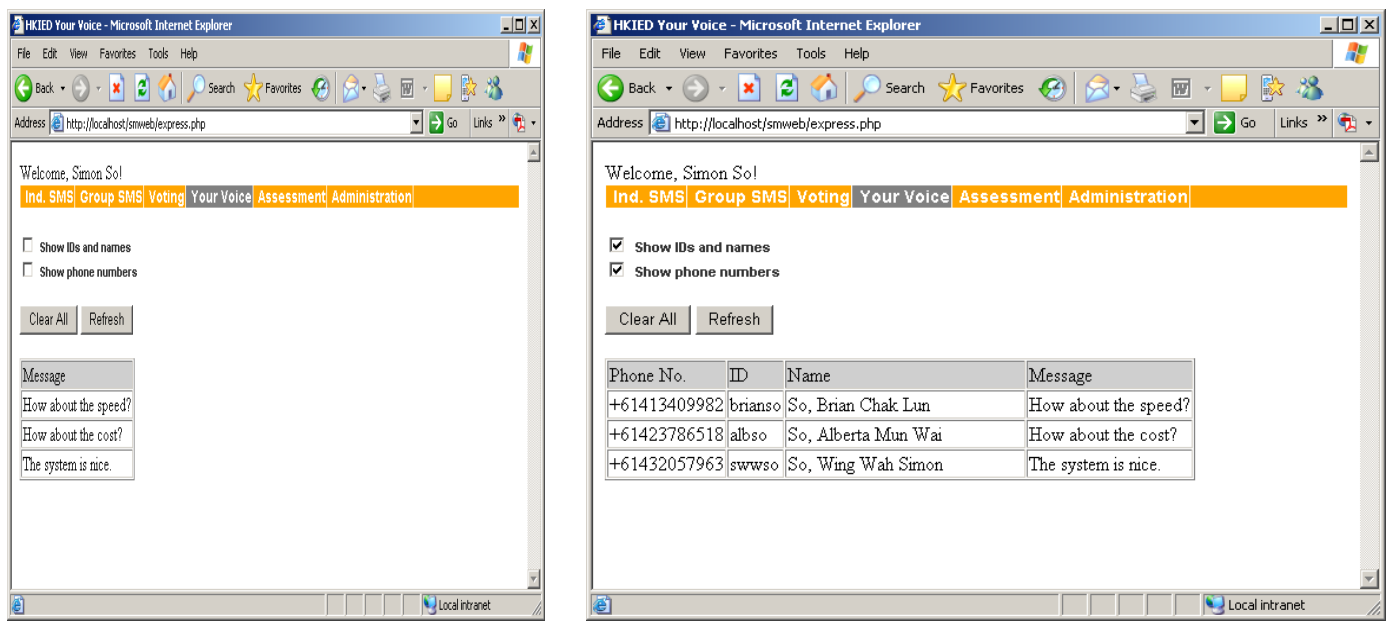

Figure 8. Brainstorming Activities 

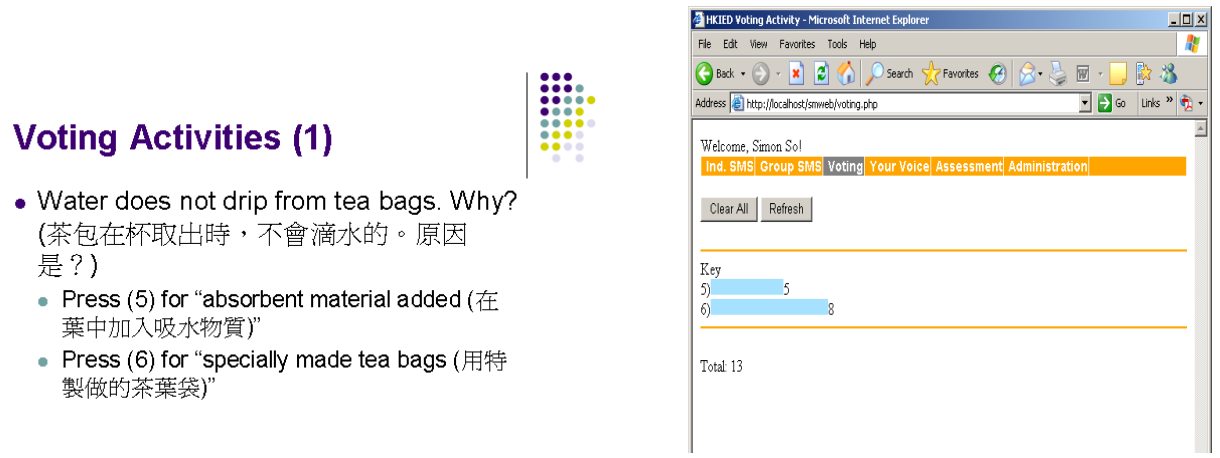

Figure 9. Voting Activities

Assessment is an integral part of any teaching and learning activity. It influences student motivation and learning. Increasingly, as technology advances, teachers become more proficient to use computer-based techniques for assessment. Features such as item banks, electronic grading, and computeradapted testing are readily available in many commercial e-learning systems. Our SMSbased teaching and learning system provides a facility for teachers to carry out assessment. Teachers can compose item banks in Excel. The system supports a variety of question types such as multiple-choices, short answers, and a sequence of touch-key answers. Figure 10 demonstrates the process.
A series of activities were conducted using our SMS-based teaching and learning system to students as shown in Figure 11. These are preservice teachers taking a course in Networking for Bachelor of Education (Primary). Normally, the lectures are conducted in a computer lab, but the author implemented some of the activities using the SMS-based teaching and learning system instead as depicted in Figure 11. Figure 10 reviews some of the questions the author asked during the lecture. Overall, the students enjoyed the innovation and found the series of activities described above quite stimulating.

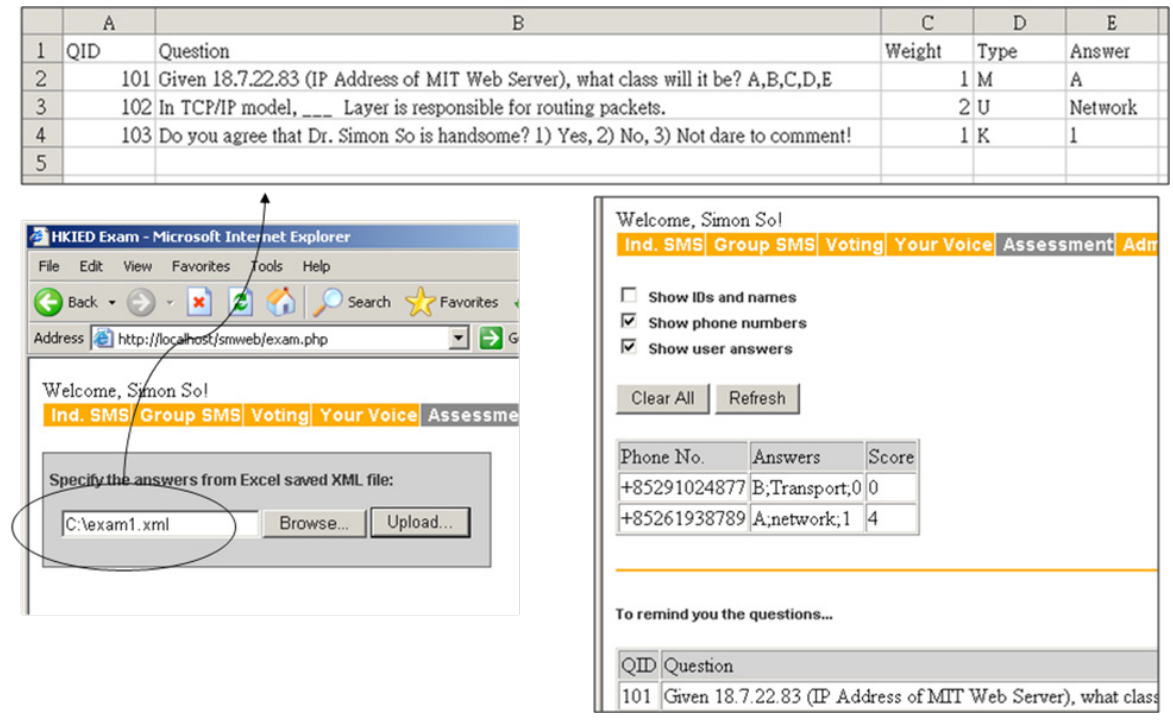

Figure 10. Assessment 

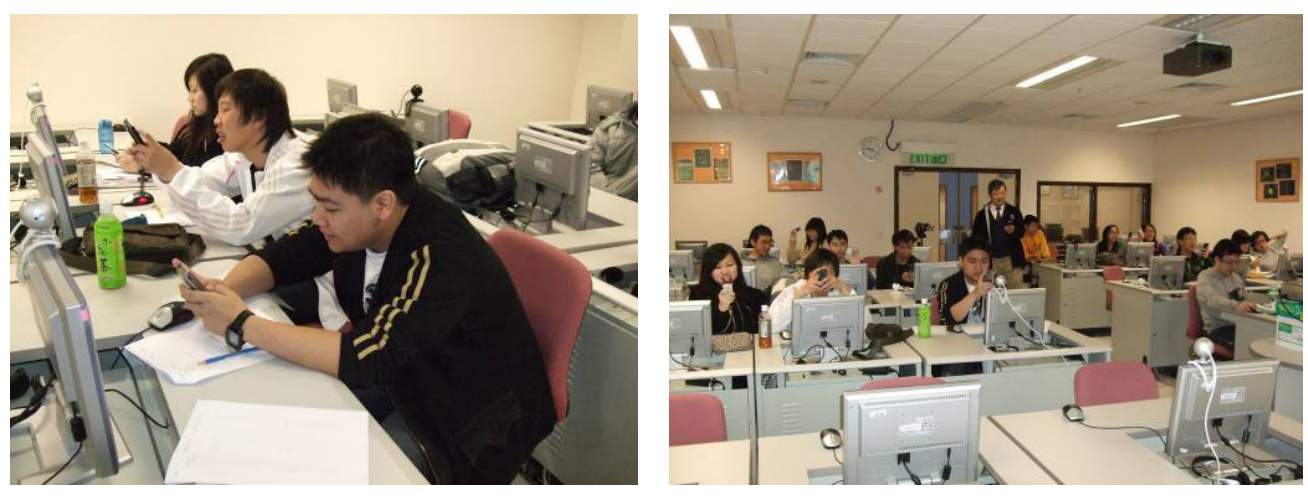

Figure 11. SMS-based Learning Activities

\section{Limitations of the System}

As pointed out earlier in the paper, this approach has the advantage due to basic mobile phones readily available to students. Ubiquitous access is the most eminent aspect of the system. The system, however, cannot be used in isolation or as the replacement of other traditional e-learning means to support teaching and learning. We recognize there are a number of limitations. Firstly, SMS technologies can only be used to provide byte-size content or interaction. Simple texting is not suitable for many teaching and learning scenarios. Secondly, although the cost to send and receive SMS messages is small, it is a major concern for repeated interaction between the providers and the learners. Some solutions to this problem do exist. For examples, the providers can make bulk purchases of SMS services from the mobile carriers. In some countries, they can also take advantages of the free exchange of SMS messages within the same mobile carriers (by using a farm of GSM modems to reach out the different mobile carriers and "dipping"). Nevertheless, the operational cost can be a prohibitive factor for SMS-based teaching and learning activities to some providers. Other limitations include small-form factor, one-finger operation, battery, and slower transmission speed of SMS messages. These are all valid issues of the system.

\section{Conclusion}

In this paper, the development of a SMS-based teaching and learning system is described. GSM modems are used to support teaching and learning needs. For small and medium operations, our approach of using GSM modems to implement the system is ideal from the perspectives of cost and data volume. The technical aspects for such a system are revealed and the system can be expanded by incorporating a farm of GSM modems.

The teaching and learning considerations of the system are also presented. We argue our system from the theoretical framework of Tool, Tutor, and Tutee which are loosely equated to communication and administrative support, teaching, and learning respectively. A number of pedagogical considerations such as brainstorming, voting, and assessment are presented.

The limitations of the system are also revealed. In spite of the concerns, we believe that our system can enhance both student's and teacher's teaching and learning experiences that are different from the traditional e-learning system by taking advantage of the ubiquitous nature ofmobile phones and the readily available infrastructure of short message services. 


\section{References}

Bollen, L., Eimler, S., \& Hoppe, H. (2004). SMS-based Discussions - Technology enhanced collaboration for a literature course. Proceedings of the $2^{\text {nd }}$ IEEE International Workshop on Wireless and Mobile Technologies in Education (pp 209210), IEEE Computer Society.

Cavus, N., \& Ibrahim, D. (2009). M-Learning: An experiment in using SMS to support learning new English language words. British Journal of Educational Technology, 40(1), 78-91.

Cui, G., \& Wang, S. (2008). Adopting cell phones in EFL teaching and learning. Journal of Educational Technology Development and Exchange, 1(1), 69-80.

Deakin. (2009). Results schedules and access information: Accessing results. Deakin University. Retrieved March 6, 2009, from http://www.deakin.edu.au/current-students/ study-information/exams-assessment/ results.php

Developershome. (2008). SMS Tutorial: Introduction to wireless modems, GSM modems and GPRS modems. Retrieved June 1, 2008, from http://www.developershome. com/sms/GSMModemIntro.asp

DUKE. (2009). Personal response system. Center For Instructional Technology, Duke University. Retrieved March 6, 2009, from http://cit.duke.edu/tools/classroom/prs.html

Goh, T., \& Hooper, V. (2007). To TxT or not to TxT: That's the puzzle. Journal of Information Technology Education, 6, 441453.

Hill, J., Hill, C., \& Sherman, D. (2007). Text messaging in an academic library: Integrating SMS into digital reference. The Reference Librarian, 47(1), 17-28.

HKIED. (2009). Library SMS alert service. Hong Kong Institute of Education. Retrieved on March 6, 2009, from http://www.lib.ied. edu.hk/collection/sms.html

Hoppe, H. (2004). SMS-based discussions - Technology enhanced collaboration for a literature Course. Proceedings of International Workshop on Wireless and Mobile Technologies in Education, National Central University, Taiwan.

Islam, Y., \& Doyle, K. (2008). Distance education via SMS technology in Rural Bangladesh. American Behavioral Scientist, 52(1), 87-96.

Levy, M., \& Kennedy, C. (2005). Learning Italian via mobile SMS. In A. KukulskaHulme, \& J. Traxler (Eds), Mobile Learning: A Handbook for Educators and Trainers (pp 76-83). London: Routledge.

Kennedy, C., \& Levy, M. (2008). L'italiano al telefonino: Using SMS to support beginners' language learning. European Association for Computer Assisted Language Learning, 20(3), 315-330.

Lu, M. (2008). Effectiveness of vocabulary learning via mobile phone. Journal of Computer Assisted Learning, 24, 515-525.

Markett, C., Arnedillo Sánchez, I., Weber, S., \& Tangney, B. (2006). Using short message service to encourage interactivity in the classroom. Computers \& Education, 46, 280-293.

Martínez-Torres, M., Toral, S., Barrero, F., \& Gallardo, S. (2007). Improving learning performance in laboratory instruction by means of SMS messaging. Innovations in Education and Teaching International, 44(4), 409-422.

Naismith, L. (2007). Using text messaging to support administrative communication in higher education. Active Learning in Higher Education, 8, 155-171.

Ng'ambi, D. and Brown, I. (2009). Intended and unintended consequences of student use an online questioning environment. British Journal of Educational Technology, 40(2), 316-328. 
Pincas, A. (2004). Using mobile phone support for use of Greek during the Olympic games 2004. Proceedings of MLEARN 2004, Odescalchi Castle, Lake Bracciano, Italy.

Pramsane, S., \& Sanjaya, R. (2006). Mobile education services based on SMS and their architecture comparison. Proceedings of the Third International Conference on eLearning for Knowledge-based Society, Bangkok, Thailand.

Schick, C. (2007). The mobile lifestyle: How the fusion of the mobile and the Internet have changed the way we live, learn, and play. Keynote Speaker of the 6th International Conference on Mobile Learning. Melbourne, Australia.

Scornavacca, E., Huff, S., \& Marshall, S. (2007). Developing a SMS-based classroom interaction system. Proceedings of the Conference on Mobile Learning Technologies and Applications (pp. 4754). Massey University, Auckland, New Zealand.

Scornavacca, E., Huff, S., \& Marshall, S. (2009). Understanding the value of interactive SMS for large classes. In H. Ryu and D. Parsons (Eds), Innovative mobile learning: Techniques and technologies (pp 48-58). Hershey, PA: Information Science Reference.

Stead, G. (2005). Moving mobile into mainstream. The 4th World Conference on mLearning. Retrieved March 6, 2009, from http://www.m-learning.net/links/papers/ MLearn2005_Stead.pdf

Taylor, R. (1980). The computer in the school: Tutor, tool, tutee. New York: Teacher's College Press.

Telstra. (n.d.). Telstra online SMS business. Retrieved June 1, 2008, from http://www.telstra.com/countrywide/ telstramobility/resources/pdf/online_sms_ brochure.pdf?SMSESSION=NO

Thornton, P., \& Houser, C. (2001). Learning on the move: Vocabulary study via e-mail and mobile phone SMS. In C. Montgomerie \& J. Viteli (Eds.), Proceedings of World Conference on Educational Multimedia, Hypermedia and Telecommunications 2001 (pp 1896-1897), Chesapeake, VA: AACE.

Thornton, P., \& Houser, C. (2005). Using mobile phones in English education in Japan. Journal of Computer Assisted Learning, 21, 217-228.

Traxler, J. (2005). Case studies: Introduction and overview. In A. Kukulska-Hulme and J. Traxler (Eds), Mobile learning: A handbook for educators and trainers (pp 70-75). London: Routledge.

Viljoen, J., Preez, C., \& Cook A. (2005). The case for using SMS technologies to support distance education students in South Africa. Perspectives in Education, 23(4), 115-122.

Wen, D., Xiong, J., Ally, M., \& Lin, F. (2006). An SMS based querying system for mobile learning. The Fifth World Conference on Mobile Learning. Banff, Alberta.

\section{Contact the Author}

Simon So, Ph.D.

Hong Kong Institute of Education, HK

E-mail: swwso@ied.edu.hk 